\title{
From Marshall Poe
}

In the fall of 1999, I decided that it was high time that the field of Russian studies had a good published English translation of Gregorii Kotoshikhin's remarkable Russia in the Reign of Aleksei Mikhailovich. There is no better introduction to Muscovite Russia than this book. I knew that Ben Uroff had translated the text in his 1970 Columbia University dissertation. More accurately, everyone who worked in the field knew that Ben had translated it because everyone in the field had used it. Never had there been a more popular dissertation. I had a well-worn copy myself. Ben's dissertation was and remains a remarkable piece of scholarship. To call it simply an "annotated translation" is to freight the word "annotated" with a weight it cannot bear. The dissertation is a sort of encyclopedia of Old Russia with Kotoshikhin providing the main entries and Ben filling in all the details. And I mean all the details. The "annotation" contains close to 1,000 long, discursive, reference-heavy footnotes taking up over 300 pages. If you want to know about something in Muscovy, Ben's dissertation is a good place to start.

I wondered why Ben hadn't published his thesis. I had never met him, so I had never had the opportunity to inquire. I asked around and discovered that Ben was a bit of a mystery. A few people had met him at Illinois, where Ben taught for many years, either during graduate school or while attending one of the university's summer workshops. But even they couldn't say much about him. I pursued the case no further and set about drafting my own translation.

I didn't get far. I translated a few pages and then decided to check them against "Uroff.” This was discouraging, because "Uroff” was better every time. I gave up and decided to write Ben to ask if he'd like help preparing the book for publication. Yes, he responded, he'd love to publish the book. It seemed as if he'd been waiting for someone to ask. And so we started our partnership. Ben seemed to enjoy the entire process-preparing and revising the manuscript, drafting the publication prospectus, and working toward eventual publication of the work.

Alas, Ben passed away in October, 2005, before he could see the book in print. This is sad, there is no other word for it. But I take solace in the fact that in his last years he knew that his great work would finally be published. I also think he would be pleased with the result. The translation is almost entirely his, just as it was found in his dissertation. I have made certain alterations, primarily to bring Ben's words into line with current scholarship. Since 1970 we have learned much about Muscovy. We have also learned a lot about Kotoshikhin and his text, thanks largely to the efforts of the late Ann E. Pennington. Her O Rossii v tsarstvovanie Alekseia Mikhailovicha. Text and Commentary (Oxford: Oxford University Press, 1980) provides what is now and likely will forever be the definitive edition of Kotoshikhin's work from a linguistic point of view. Ben did not have access to this book, though he had and used Pennington's dissertation “The Language of Kotoshikhin” (Oxford University, 1965). If Ben had had Pennington's edition, he surely would have used it. He told me as much. So I felt no hesitation in using it to fine-tune Ben's rendering. 
This book is an edition of Ben's translation, first published in his dissertation "Grigorii Karpovich Kotoshikhin, On Russia in the Reign of Alexis Mikhailovich: An Annotated Translation" (Columbia University, 1970). It is intended to make an English text available to students and non-specialist scholars who might not otherwise have access to Kotoshikhin's work. Muscovite-era experts will of course want to use Pennington's Russian edition, and they will know that there is an extensive literature devoted to Kotoshikhin, much of which can be found simply by searching scholarly databases such as JSTOR or Project Muse. Because this book is meant for nonspecialists, I made a number of changes to Ben's original work. I characterize them below.

\section{Commentary}

Ben's commentary on Kotoshikhin is a scholarly tour de force. Though it remains very valuable today, only area experts are likely to need or use it. Given this consideration and the fact that Ben's dissertation is readily available online via ProQuest Dissertations, I have-with some regret-omitted his fine notes from the present edition.

The reader will find footnotes in Kotoshikhin's text below. These, however, are Kotoshikhin's own marginal notes, that is, they are found in the original manuscript.

\section{Syntax}

Ben tried to be true to Kotoshikhin's sentence structure, which is often difficult to render in English. He succeeded, but it must be said that the results can be tough going. This is no fault of Ben's. Kotoshikhin was not used to writing long descriptive sentences-exactly the kind the Swedes wanted him to write-so he sometimes got a bit tangled in his own words. Ben restored as much order as there was to restore, and thereby offered the reader a good impression of what it is like to read Kotoshikhin in the original. It would be graceless to ask for more, and would probably do violence to the meaning of the text. In a very few places I have altered the syntax to give a clearer indication of Kotoshikhin's intent, or what I believe to have been Kotoshikhin's intent.

\section{Lexicon}

Ben was extraordinarily careful in selecting English words and phrases that telegraphically related the meanings of Kotoshikhin's words and phrases. Yet he knew that Kotoshikhin used some terms that either have no good equivalents in English or that had confounded modern scholars. How should one translate a word like dvorianin? Dvor means (inter alia) "court." So is "courtier" the right term? No, not really, as dvoriane usually didn't serve at court. Following the standard practice of the field, Ben opted not to translate difficult terms at all. So dvorianin appeared as "dvorianin" in his dissertation. This has put me in something of bind. On the one hand, Ben's expert-focused strategy won't do as this book is intended for general readers, none of whom will have any interest in trying to figure out what the word "dvorianin" 
really means. On the other hand, it would be wrong to suggest that "nobleman" (the term I use) captures all-or even most-of the nuances of " $d$ vorianin." The compromise I have employed is this: I have translated Ben's untranslated words and placed the Russian terms in square brackets next to them. So one reads "nobleman [dvorianin]." I'm mindful of the fact that this practice may be a bit distracting, but serving two masters-in this case, general readers and scholars-is never easy. A glossary of all the terms Ben left untranslated is found in Appendix 1 below.

The single exception to this rule is the court rank "okol'nichii," the rank immediately below boyar in the royal council. Most scholars agree that there is no good English equivalent for this term, so I have left it untranslated throughout.

\section{Weights, Measures, and Currency}

Ben did not translate the weights, measures, and currencies found in Kotoshikhin. Rather, he left the original terms and explained each one as it appeared in the text. I, too, have left these terms untranslated, though I have provided an explanation of them in Appendix 2 below.

\section{Pagination}

Ben's used A. Barsukov, ed., O Rossii v tsarstvovanie Alekseia Mikhailovicha (St. Petersburg: Tip. Glavnago upravleniia udelov, 1906) as the basis for his translation. He did not provide any indication of the pagination found in the original manuscript, which I do not believe he ever saw. Pennington, however, used the original manuscript (found in the library of Uppsala University) as the basis for her edition and provided manuscript page numbers. Using Pennington's edition, I have taken the liberty of inserting the folio numbers in the appropriate places in Ben's translation. Thus " $\left\{106^{\mathrm{v}}\right\}$ " indicates the beginning of folio 106 verso in the manuscript as described by Pennington. The placement of the folio numbers is only approximate, but should be of some use to experts looking up this or that word, sentence, or passage in Pennington.

\section{Table of Contents}

Ben followed the edition he was translating and placed Kotoshikhin's table of contents at the back of his rendering. This also reflects the manuscript, where the table falls on folios 234 to 249. Following the English custom, I have moved the contents to the front of the book.

In closing, I would like to thank Charles Halperin, Daniel Kaiser, Edward Keenan and the members of $\mathrm{H}$-EarlySlavic for their help in the preparation of this book.

Marshall Poe

Smith College, Northampton, Massachusetts 